\title{
6 \\ Multi-sited fieldwork in regulatory studies
}

\author{
Kathryn Henne
}

\section{Introduction}

Studying regulation, as the other chapters in this book attest, can be a complicated process. The previous chapter provides guidelines regarding the theoretical and methodological concerns that we as researchers should consider critically before conducting research on regulation. It emphasises the importance of studying objective concerns, such as regulatory enforcement and whether or not actors comply, alongside subjective ones, such as the meanings attributed to regulation as influenced by participants' world views. This chapter acknowledges those important considerations, but focuses on the particular concern of accounting for the transnational dimensions of regulation. While both objective and subjective concerns inform regulation, so, too, do the globalised undercurrents shaping broader social change.

This chapter discusses the use of multi-sited fieldwork methodology to document and analyse the many factors that emerge across structural, systemic and local levels. This approach requires field-intensive qualitative methods, which include, but are not limited to, participant observation, interviewing, fieldnote taking, archival and document analysis, audio and/or visual recording and sustained interactions with participants. Regulatory regimes are made up of processes that exceed 
written laws and rules; they entail a 'range of policies, institutions and actors' (Scott 2010: 1). As a result, regulation makes for an unwieldy and unpredictable object of inquiry. It can be difficult to document and account for the number of actors, practices, spaces and norms that contribute to regulation, yet alone understand how they contribute. In addition, it is not always possible to identify the key actors, mechanisms and principles within a regime at the start of a research project. How, then, do we go about studying regimes, which may—or may not—have clear boundaries and regulatory webs? How do we discern which actors, mechanisms, principles and processes matter? How do they interact in practice? The foundational assumptions and methods of multi-sited fieldwork offer guidance in answering these questions.

Multi-sited analyses have traced how regulatory regimes influence various fields of social activity. Recent studies have examined a wide range of domains of regulation and governance, including global environmental politics (Downie 2014), internet governance (Tusikov 2016), global mining standards (Dashwood 2012) and international sport (Henne 2015). These studies, although examining distinct arenas of activity, point to the many ways that the development and expansion of regulation both respond to and reflect globalised changes. Others, such as Paul Verbruggen (2014) in his research on advertising and food safety, do not limit their focus to a single regime or social arena. Verbruggen looks at two distinct regimes to study the broader institutional design of transnational private regulation. Studying both spaces helps in discerning the weaknesses of private enforcement mechanisms and the role of courts in enforcement. Despite their different foci, this body of regulatory research shares a common concern: to describe and explain how regulation is embedded in world systems.

Globalised systems have major impacts on the study of regulation and its concepts. Regulatory capitalism, for instance, is a broad trend (see Levi-Faur,Chapter 17, this volume) that demonstrates how the pursuit of capitalistic growth often gives rise to more-not less-regulation and bureaucracy. That said, regulatory capitalism has not emerged uniformly across the globe; it takes on specific contexts and contours in different spaces. Researchers therefore should be attuned to localised concerns as well as to globalised shifts that inform their studies. Accordingly, carrying out field research on regulation requires careful consideration of how global, national and transnational systems and discourses inform what we observe as researchers. Other disciplines share this preoccupation. 
For example, anthropologists have employed what is often referred to as 'multi-sited ethnography' to describe and analyse how people, objects, ideas, symbols and commodities circulate and become interconnected within transnational processes of globalisation (Marcus 1995). The drive for multi-sited ethnography is as much theoretical as methodological: it advances a notion of connectivity—one that assumes a 'local' site is linked to a broader set of globalised relations. In doing so, this approach requires the ethnographer to follow those relationships empirically.

While some anthropologists are dismissive of multi-sited ethnography (for example, Candea 2007), we would be remiss not to acknowledge some of its parallels with regulatory studies. Regulatory scholarship retains a critical focus on how different actors, ideas, objects and events inform governance structures, institutions and practices. The regulatory theories and concepts discussed in other parts of this book reflect the importance of understanding systems, webs and networks in making sense of regulatory and governance practices. As regulatory scholarship is not confined to anthropological conventions, the study of regulation has given way to a distinctly interdisciplinary tradition of multi-sited fieldwork. This chapter outlines core concerns underpinning multi-sited studies of regulation. It addresses complementary schools of thought, such as multi-sited ethnography, and how regulatory studies brings together seemingly varied approaches to fieldwork under an interdisciplinary umbrella. This chapter is organised by a series of questions that target substantive and methodological issues in regulatory studies. Together, the sections of this chapter provide an overview of the practices and challenges of multi-sited fieldwork.

\section{What kinds of regulatory research problems and questions does qualitative fieldwork address?}

Field-intensive methods facilitate the gathering of in-depth data on the relationships between events, behaviours and context, because they require three research practices that other methods do not: the direct observation of social actions as they take place, the accounting of events that come before or after such actions and the consideration of how the resulting behaviours are understood by 'participants and spectators, before, during and after its occurrence'(Becker and Geer 1957:28). The emphasis of field- 
intensive methods on observing relationships yields robust information on the connections between events and behaviours, which interview or survey methods alone cannot capture (Jerolmack and Khan 2014). In relation to law and regulation, qualitative fieldwork enables researchers to document relationships between the events, social conditions and actors that shape regulation and to analyse how participants' perceptions and social context inform the meanings attributed to regulation.

Fieldwork enables a better grasp of how regulation operates in practice, particularly how it can reflect or diverge from written rules. Kitty Calavita (2010: 9) summarises this distinction and its importance:

Noting that the law as it is written and advertised to the public is often quite different from the way it looks in practice, law and society scholars have long had an interest in studying that gap.

The gap to which Calavita refers can manifest in a variety of ways, taking on different forms as conditioned by their context. Consider Losoncz's (2015) analysis of how Australian government policies and programs inform the resettlement strategies of migrants. She draws on sustained fieldwork to unearth how mechanisms developed to ensure equal access among citizens fail to secure such rights to humanitarian and other migrant groups. These processes, by failing to account for the marginalisation and cultural values of many migrant groups, actually block pathways to social and economic security, prompting some groups, such as South Sudanese refugees, to disengage from government, community and social institutions. As Losoncz's work demonstrates, in-depth fieldwork can provide significant insight into the social actors and milieu of regulation. This focus echoes legal-realist principles that embrace 'a ground-level up perspective' that illuminates how law and regulation impact people in everyday life, be they elites or ordinary residents (Suchman and Mertz 2010: 561). Unlike legalformalist values, their scope is not limited to formal law.

It is important to note that law is just one form of regulation. As such, regulation encompasses myriad forms of social control and a wide array of social activities. The interests of regulatory specialists, in turn, often diverge from the traditional foci of law and society scholarship. For example, rather than engage the longstanding socio-legal debates about what counts as law in society (see Calavita 2010), scholars of regulation are more interested in questions about how regulatory orders emerge, take on meaning and come to influence behaviour. Law, according to David Levi-Faur (2011: 5): 
cannot save us from the recognition that there are many ways in which regulation enters the public and academic discourse. Instead of forcing unity, we need to recognise the many meanings of regulation.

Qualitative studies of regulation are thus keenly attuned to how multiple instruments and techniques of regulation interact when mobilised.

A mainstay of regulatory research is its engagement with regulatory pluralism. Regulatory pluralism, as explained by Neil Gunningham and Darren Sinclair (1999: 49), encompasses a 'much wider range of policy mechanisms' than traditionally assumed of law and policy, including 'economic instruments, self-regulation, information-based strategies, and voluntarism'. Take, for example, the differences between regulatory pluralism and legal pluralism and their study (see Forsyth, Chapter 14, this volume). Legal pluralism, as a concept, captures the diversity of legal systems and normative orders, which often have formal and informal dimensions operating simultaneously (Forsyth 2009). Legal pluralism was first observed in colonial societies in the exercise of colonial and customary law, but the concept has since been extended to understand other domains, including postcolonial settings where customary and state law coexist and hybrid regimes that combine multiple regulatory strategies. For example, Miranda Forsyth's (2009) research in Vanuatu illuminates the challenges of two systems coexisting, which are exacerbated because the state system does not officially recognise the kastom system (the nonstate, customary system administered by chiefs). Regulatory pluralism certainly overlaps with these concerns, but accounts for various regulatory instruments, which may have customary, colonial or hybrid origins.

The differing focal points of legal pluralism and regulatory pluralism have yielded distinct, though arguably compatible, empirical insights. Qualitative studies of legal pluralism-notably, the contributions of legal anthropology - provide important methodological and analytical approaches to studying law in action, even in situations when some forms of social control are not recognised as law. Such contributions include the trouble case approach, which looks at disputes to identify 'the trouble' and how it was resolved; processual analysis, which examines the means of settling disputes; and the acknowledgement of semi-autonomous social fields, which appreciates that different legal orders are not autonomous and affect how other orders operate (Forsyth 2009). 
Although these represent important analytical breakthroughs in the study of law, the recognition of global legal pluralism-that is, forms of pluralism that extend beyond the boundaries of the nation-statehas challenged the applicability of some earlier approaches. Multisited regulatory scholarship offers an important intervention, because it considers pluralistic spaces in which law may or may not be present. For example, wireless communication standards that shape the direction of information technology are not set by global legal organisations such as the United Nations (UN) agency the International Telecommunications Union (ITU), but by standards-setting bodies such as the Institute for Electrical and Electronics Engineering. These organisations operate through voluntary participation, not through legalised enforcement mechanisms. The study of regulatory pluralism can thus better capture the array of regulatory tactics and their interplay across different social orders.

Through the empirical scrutiny of regulatory pluralism, scholars have levied analytical challenges to foundational socio-legal ideas, among them reconsiderations of the core characteristics of the state (Braithwaite 2000) and citizenship (Henne 2015). John Braithwaite's analysis of the 'new regulatory state' contends that contemporary forms of governance and social relations no longer reflect a welfare state model. As a result, Braithwaite (2000: 222) argues, social science disciplines must reorient their approach if they are to engage new problems as states embrace market competition, privatised institutions and decentred forms of regulation. Moreover, the critical study of regulatory regimes and their influence across jurisdictions emerges as an equally important task. Multi-sited field research offers two interrelated contributions: it enables a robust empirical explanation of multi-scalar and cross-jurisdictional phenomena and can, in turn, aid in generating new concepts to better respond to governance challenges. The next section elaborates on the features and methods of multi-sited fieldwork.

\section{What is multi-sited fieldwork?}

Multi-sited fieldwork is most often discussed in relation to ethnography. Ethnography, as a methodology, is traditionally described as the systematic study of a population in a particular location through long-term field research. Although considered a robust methodology for understanding localised cultural dynamics and describing what actors do in these spaces, 
ethnography has clear limitations. Colin Jerolmack and Shamus Khan (2014: 181) characterise them as a lack of 'generalisability beyond those actually studied' and 'difficulty accounting for social structure'. Different methods are thus better suited for certain kinds of research questions. For example, 'the study of macro changes in birth, death, and fertility rates is best left to demographers' (Jerolmack and Khan 2014: 181). While this is an important point about the appropriateness of methods, it is a misnomer to assume that field-intensive research can only be conducted in one location with immersion achieved only through a long period in that location.

Multi-sited ethnography - a term coined by anthropologist George Marcus (1995) - is the practice of producing in-depth research attuned to the influence of world systems. World systems theory posits two central tenets: first, that capitalism supersedes geographic boundaries in significant ways that shape relationships between nations and across the globe, and second, that macro-level examinations are necessary to understand how capitalism informs global inequality (Wallerstein 2004). Multi-sited ethnography gleans insights into these macro-level developments through the close study of commodities, objects, persons and ideas as they travel across time and space. In essence, it uses methods traditionally associated with the study of micro-level phenomena (for example, participant observation, interviewing, sustained interactions with participants) to make sense of larger-scale processes. For Marcus (1995), research methods may focus on small-scale interactions, but they need to attend to how they take shape in world systems. Rather than making sense of cultural changes through the sustained analysis of one community, a multi-sited ethnographic approach entails 'following' objects of inquiry, which can include things (such as gifts, money and other objects), people, signs and metaphors, stories and narratives, life histories and biographies, as well as conflicts (Marcus 1995: 106-13). This definition may at first seem abstract, but, in keeping with the conventions of ethnography, it focuses on observable relationships.

Consider how Kim Fortun (2001) studied advocacy on the behalf of the thousands of victims affected by the 1984 Union Carbide gas tragedy in Bhopal, India. ${ }^{1}$ The incident remains a globally recognised industrial disaster-a seemingly clear case of regulatory failure. A traditional

1 Official estimates vary, but the gas leak and explosion exposed over 500,000 people to methyl isocyanate gas and other chemicals. 
anthropologist may have an interest in the transnational flows that shaped the disaster and how they informed responses to it, but she would not necessarily leave India to do so. Instead, a classical anthropological approach is more likely to produce an in-depth analysis of the changing dynamics within Bhopal over the years following the disaster. Fortun spent substantial time in India; however, in pursuing the multiple forms of advocacy that emerged in response to the Bhopal disaster, she also studied transnational advocacy networks and responses from international corporations. Her research questions and methodology required her to go to spaces where she could examine different court reactions in the United States and India, how Union Carbide designed plant sites and even how trade agreements being signed by India influenced domestic discourses while the Indian Supreme Court decided the Bhopal case. As Fortun's work demonstrates, multi-sited ethnography prompts the researcher to be attentive to changing circumstances during fieldwork, including their globalised dimensions. Accordingly, there is a methodological imperative to trace the various relationships informing them, which often requires following the flows to other field sites. It involves adding sites until you arrive at a better explanation of the problem. Whereas the traditional anthropologist obtains immersion by remaining in one space, the multi-sited ethnographer traverses spaces to understand the contours of phenomena.

Multi-sited ethnography aids in examining transnational processes that do not map neatly on to global, national or local levels. Marcus (1995) underscores three important areas of focus on actors, objects, ideas, symbols and stories: how they circulate; how they coalesce and diverge; and how their relationships reflect and contribute to existing systems of knowledge as well as the production of new forms of knowledge. The principles underpinning multi-sited ethnography reflect its theoretical subscription to global connectivity. It can be difficult, however, to see how this description lends itself to a distinct methodology-and this is perhaps part of Marcus's point. That is, because this approach recognises that many research problems are conditioned by transnational circulation, an overly prescriptive methodology might undermine the dynamism required for multi-sited inquiry.

Ethnographies of globalisation provide guidance in terms of how to go about designing and carrying out a multi-sited project. Anna Tsing's (2005) study of how corporate growth changed the rainforests of Indonesia serves as a case in point. She illustrates how an array of capitalist 
interventions (many backed by regulatory instruments) transformed Kalimantan's forests and the lives of many residents in Borneo during the 1980s and 1990s. To do so, she traces a series of developments that shaped the area's transformation: the discursive framing of the area as a 'frontier' ripe for resource extraction, the contingent alliances between corporations and local residents, the treatment and responses of the Meratus Dayak community - who live deep in the rainforests and are considered 'the disorderly cousins of the civilized people in surrounding plains and towns' (Tsing 2005: 174)—and the rise of a domestic environmental movement that vehemently opposed the devastation of the forests and their inhabitants. In detailing the relationships between these actors and the landscape, Tsing illuminates broader structural changes that led to rapid commercial changes and the Dayaks' disenfranchisement. Reminding her readers that globalisation is not delivered 'whole and round like a pizza' (Tsing 2005: 271), she describes how globalisation reconfigured the region through a series of fragmented encounters that included dealings with entrepreneurs and conflicts between local residents, activists, scientists, private investors and funding agencies. Rather than a clash of cultures, Tsing argues, globalisation results in sometimes awkward frictions. These frictions expose unequal forms of exchange that can yield 'new cultural and power dynamics through the fragmentary intersection of ideas and concepts at global/ local scales' (Levitt and Merry 2009: 445). In doing so, her analysis demonstrates how multi-sited ethnography enables deeper scrutiny of the power relations underlying these structural changes.

By attending to localised conditions in individual sites as well as the relationships between them, multi-sited ethnography accounts for context in critical ways that thin interpretations based on geographic case studies can fail to do (Bartlett and Vavrus 2014). This approach enables the identification and analysis of activities that exist beyond state-sanctioned boundaries by tracing circulations, 'shifts, technoscience, circuits of licit and illicit exchange, systems of administration or governance and regimes of ethics or values' (Collier and Ong 2005: 4). According to Sally Engle Merry (2015), ethnography's emphasis on localised and contextual dynamics offers important insights into how we think about the global. In fact, as Philip McMichael (1996: 50) explains:

Global relations are inconceivable without local 'faces,' just as the 'local' has no meaning without context. The very definition of 'global' and 'local' are not only mutually conditioning, they continually change. 
For Merry (2015), examining smaller sites of sociality is critical to understanding the everyday actions that take place in international spaces, which are sometimes thought of (incorrectly) as abstract and far removed from the local. Instead, she argues, the global is a particularly important set of localised interactions between influential actors, which have ripple effects across other locales.

Merry (2015) outlines specific kinds of ethnography that can illuminate transnational dimensions: deterritorialised ethnography, which studies spaces that are not based in a particular geographic locale but exist internationally, such as UN conferences; contextualised ethnography, which examines how a local site is embedded in larger social systems, networks and practices; and the analysis of commensuration, which is the process of translating diverse social conditions and phenomena into comparable units. Processes of commensuration are important, because they actually decontextualise people, events, actions and objects to create points of comparison and similarity. Merry (2011) has analysed their power. Specifically, she has studied the expansion of quantitative measures used to evaluate the efficacy of international legal intervention, which often disavow the importance of context. In contrast, Merry brings attention to the particular conditions informing the development of indicators, how these measures have come to have global currency and the consequences of their privileging over other forms of knowledge. Within this in mind, formulaic approaches to research design and practice cannot capture the variety of ways to account for the transnational dimensions of social phenomena and processes. Fieldwork can take place in different sites across the globe or in strategically situated sites where a researcher or research team can observe and connect relationships beyond a particular locale. Thus, and importantly for studies attentive to world systems, the researcher needs to pay careful attention to transnational connections as well as to site-specific distinctions. This can require the reconsideration of both spatial and temporal influences and their bearing on one's research design, objects of inquiry and data. Doing so can actually lead to the revision of one's initial research questions, which is a benefit as well as a challenge of adopting this approach.

There are other words of caution for the aspiring multi-sited fieldworker. It can be difficult to ascertain the level of immersion, as ethnographic research that traditionally relies on long-term fieldwork within a particular space or community. Regulatory researchers, however, are not necessarily bound to the conventions of anthropological inquiry. 
Instead, the interdisciplinarity of regulatory studies yields different obligations: the difficult duty of explaining and justifying a multi-sited approach to scholars from a range of backgrounds. The next section offers a discussion of a few-certainly not all-examples of multi-sited regulatory research, each adopting a distinct approach that attends to different demands of their research questions and sites.

\section{How have scholars of regulation used multi-sited fieldwork methods?}

Multi-sited studies of regulation reflect varying approaches to obtaining in-depth understandings of the transnational dimensions of governance arrangements. In terms of foundational studies of regulation, Global Business Regulation by John Braithwaite and Peter Drahos (2000) stands out as a classic text (see also Drahos, Chapter 15, this volume). It is also a pioneering multi-sited research project, drawing on interviews with over 500 participants in multiple sites across 13 cases. Braithwaite and Drahos (2000: 13) refer to their research approach as a 'micro-macro method for the anthropology of global cultures', which, they argue, requires 'a combination of the qualitative methods of anthropologists and historians'. Global Business Regulation is methodologically distinct in the sense that it is, for the most part, not comparative, but rather global in its orientation. Its transnational character emerges through a sustained endeavour to identify and describe themes that cut across domains of business regulation.

In her work on human rights and gender violence, Merry (2006) opts for a deterritorialised approach to fieldwork. It shares the micro-macro methodological concerns expressed by Braithwaite and Drahos (2000). Her examination of the global movement to promote human rights and to end gender violence brings attention to how global and local activism converge in ways that reveal different framings of human rights issues across sites that include the United Nations, Fiji, Hong Kong, India, China and Hawai'i. In particular, she looks at how activists and other intermediaries help global human rights gain local currency, because they 'translate up and down'-that is, across the global-local interface. Translation is not the transfer of knowledge from the United Nations, but, instead, the appropriation of human rights principles to better fit localised contexts. These principles, in turn, become rooted in social practices, in ways that reflect ongoing negotiations and translations. 
Merry's work demonstrates clearly how ethnographic research can engage different parts of world systems and be used to identify synergies (as well as distinctions) between and across them. Its important contribution is not simply the depth of its investigation across sites, but also its ability to demonstrate how a deterritorialised approach can bring together disparate sites to illuminate global processes.

Multi-sited fieldwork can also be used to study a particular regulatory concern that requires consideration of different perspectives, spaces and actors. Annelise Riles (2010: 7) traces the rise of 'global private law solutions' - as outwardly distinct from direct governmental regulation of financial markets-through a focus on the role of collateral in derivatives transactions. Riles documents localised practices of and global influences on Toyko's international swap market (for example, the International Swaps and Derivatives Association, with headquarters in New York and offices in other parts of the globe) and the financial exchanges they enable. Her characterisation of regulation in this field is one marked by hybridity: it is 'neither inherently private nor public, neither global nor local'; rather, the governance of global financial markets emerges as 'a set of routinized but highly compartmentalized knowledge practices, many of which have a technical legal character' (Riles 2010: 10). While this is not an unexpected finding for regulatory scholars, her illustration reveals various manoeuvres that gloss over, and even mask, the inherent uncertainty of derivatives trades. In short, they give collateral a veneer of certainty. In light of this finding, Riles casts doubt on reforms that lack a grounded sense of routinised knowledge practices and their influence, arguing that a ground-level-up approach offers more regulatory potential. In doing so, she demonstrates how micro-level analysis can support broader recommendations.

Multi-sited research can facilitate the documentation of an emergent form of regulation, while also being attentive to broader globalised trends shaping its development and proliferation. Kate Henne's (2015) research on the relationships between antidoping regulation and gender verification ${ }^{2}$ in global sport offers one such example. It is an explicit attempt to combine multi-sited approaches used in anthropology with the micro-macro methods used by Braithwaite and Drahos (2000) to study a hybrid regulatory regime. Henne traces the history of these

2 Gender verification is a form of regulation in women's athletic events. It polices a presumed binary boundary between women and men by subjecting women to additional levels of surveillance and bodily scrutiny. 
intertwined regulations while also conducting ethnographic fieldwork on global policymaking, national and sport-specific stakeholders' strategies of compliance, forms of resistance to the regime, individual participants' understandings of the rules and athletes' experiences of navigating the mass surveillance endorsed by the regime. Looking from these different angles, she analyses how antidoping regulation shifted from a simple set of medical rules and testing implemented by private sporting organisations to a more expansive regime backed by corporatestate partnerships and reliant on various surveillance and legalistic tools. According to Henne, the regime-although attempting to preserve traditional values of fair play, bodily integrity and moral fortitude in sport-actually comes to embody many of the neoliberal values that regulators claim to stand against.

Well-designed multi-sited research can deliver robust findings without the long-term fieldwork conventionally required in anthropology to justify the depth of fieldwork. Christian Downie's (2014; see also Downie, Chapter 19, this volume) study of prolonged international negotiations on the subject of climate change provides an in-depth account without following prescribed ethnographic methods. He tracks climate change negotiations that took place between 1992 and 2013, which forecloses the possibility of participant observation and interviews across this period. To better grasp how a state changes its position in relation to the type of agreement achieved, Downie (2014: 11) examines the United States (US) and European Union (EU) during the Kyoto phase of negotiations, as both have changed their stance during negotiations and have 'traditionally been critical to the success or failure of international negotiations'. With little data on these closed-door negotiations, he relied heavily on interviews with both state and non-state elite representatives deeply engaged in the negotiations. This required multiple, iterative rounds of interviewing, enabling Downie to refine his focus. This resulted in 105 formal interviews in which participants served as important interlocutors to ensure a deeper understanding of the research problem at hand. As this example evidences, regulatory spaces are not favourable to traditional modes of ethnographic inquiry and often require strategic reconsideration and recalibration in terms of research design and planning. 


\section{What are the future directions of multi-sited regulatory research?}

Many regulatory concerns have complex, transnational dimensions, which lend themselves to multi-sited fieldwork. However, emergent problems often have features that are not easy to observe, yet alone access, for fieldintensive research. Growing concerns over big data and its retention, internet governance and the expansion of mass surveillance across a variety of domains are just a few timely examples. Natasha Tusikov (2016) documents how private-public relationships facilitate non-legally binding enforcement agreements that are altering how governments and corporations regulate content and information on the internet. Drawing on research conducted in the United States, United Kingdom, Canada and Australia, she convincingly argues that large internet companies, such as Google, PayPal, eBay and Yahoo, enable prominent multinational rights-holders and states to police vast populations across the globepractices that were technologically impossible or prohibitively expensive in the past. As these arrangements between powerful actors are secretive in nature and protected from public scrutiny, Tusikov's findings point to both the promises and the perils of multi-sited research (see also Tusikov, Chapter 20, this volume). On the one hand, multi-sited fieldwork has the capacity to shed light on otherwise invisible regulatory relationships. On the other, it entails a number of challenges in terms of obtaining access and eliciting robust information.

Given the number of transnational governance arrangements that would benefit from in-depth scrutiny, refining multi-sited research design is an ongoing process. There is a risk that a multi-sited study may not yield enough information about a research site or may obfuscate the direction of a research project by focusing too heavily on presumed connections between sites. In response to these potential limitations and challenges, Lesley Bartlett and Frances Vavrus (2014) propose the vertical case study approach as a useful model, particularly for researchers new to multisited research design. It essentially offers a guide for tracing relationships by outlining a set of axes for researchers to address in relation to each field site and then in relation to other sites. Vertical case studies help researchers identify connections and divergences across sites in ways that are attentive to how globalisation affects fields of governance without replicating the tendency of comparative approaches to overemphasise the position of the nation-state (Bartlett and Vavrus 2014). 
The vertical case study approach has three principal areas: the transversal, the vertical and the horizontal. Applied to regulatory contexts, the transversal facilitates analysis of pluralist dynamics that emerge across and through different scales. It accounts for how particular understandings of and approaches to regulatory problems circulate and become popularised within and across cases. This requires the examination of how historical, social and temporal considerations influence the development and uptake of regulatory strategies. The vertical focuses on how higher-level (for example, institutional, national, global) governance practices interact with contextual factors in ways that enable or restrain a particular technique or instrument to take hold or receive funding. The horizontal captures other grounded developments that interface with regulatory interventions (which can, in turn, have other transversal and vertical relationships not otherwise captured). The horizontal axis can include existing communal, site-specific and/or pluralistic concerns that invariably influence regulation in practice. In essence, the vertical case study can assist with mapping the distinctions of particular cases in relation to transnational regulatory relationships.

Against the backdrop of globalisation, it is difficult to study regulation without considering how it is grounded in nested systems, be they legal or otherwise. Globalisation is not an even or uniform process, nor is the emergence of regulation. Regardless of the specific design used to guide multi-sited fieldwork, an overarching concern for the field researcher is to make sense of how pluralistic orders come together and diverge. This is especially important, as regulatory pluralism does not always yield convergence. For example, labour certification and fair trade schemes are spaces in which many different standards are emerging. Such challenges make multi-sited fieldwork a particularly useful methodology for regulatory researchers. Importantly, multi-sited fieldwork provides an organising framework for micro-macro methods while prompting the researcher to be empirically attentive to the nuances of regulatory pluralism in each site. It can also be compatible with the realist underpinnings of regulatory studies by enabling the researcher to add sites as she seeks a deeper understanding of how regulation-in-action invariably deviates from rules on the books. 


\section{Further reading}

Coleman, S and von Hellerman, P 2011. Multi-sited Ethnography: Problems and Possibilities in the Translocation of Research Methods. London: Routledge.

Vavrus, F and Bartlett, L 2009. Critical Approaches to Comparative Education: Vertical Case Studies from Africa, Europe, the Middle East and the Americas. New York: Palgrave Macmillan. doi. org/10.1057/9780230101760.

\section{References}

Bartlett, L and Vavrus, F 2014. 'Transversing the vertical case study: A methodological approach to studies of educational policy as practice', Anthropology E Education Quarterly 45(2): 131-47. doi. org/10.1111/aeq.12055.

Becker, HS and Geer, B 1957. 'Participant observation and interviewing: A comparison', Human Organization 16(3): 28-32.doi.org/10.17730/ humo.16.3.k687822132323013.

Braithwaite, J 2000. 'The new regulatory state and the transformation of criminology', British Journal of Criminology 40(2): 222-38. doi. org/10.1093/bjc/40.2.222.

Braithwaite, J and Drahos, P 2000. Global Business Regulation. Cambridge: Cambridge University Press.

Calavita, K 2010. Invitation to Law \& Society: An Introduction to the Study of Real Law. Chicago: University of Chicago Press. doi.org/10.7208/ chicago/9780226089980.001.0001.

Candea, M 2007. 'Arbitrary locations: In defence of the bounded fieldsite', Journal of the Royal Anthropological Institute 13(1): 167-84. doi. org/10.1111/j.1467-9655.2007.00419.x.

Collier, SJ and Ong, A 2005. 'Global assemblages, anthropological problems', in A Ong and SJ Collier (eds), Global Assemblages: Technology, Politics, and Ethics as Anthropological Problems. Malden, Mass.: Blackwell, pp. 1-22. 
Dashwood, H 2012. The Rise of Global Corporate Social Responsibility: Mining and the Spread of Global Norms. Cambridge: Cambridge University Press. doi.org/10.1017/CBO9781139058933.

Downie, C 2014. The Politics of Climate Change Negotiations: Strategies and Variables in Prolonged International Negotiations. Cheltenham, UK: Edward Elgar. doi.org/10.4337/9781783472116.

Forsyth, M 2009. A Bird that Flies with Two Wings: Kastom and State Justice Systems in Vanuatu. Canberra: ANU E Press.

Fortun, K 2001. Advocacy after Bhopal: Environmentalism, Disaster, New Global Orders. Chicago: University of Chicago Press. doi. org/10.7208/chicago/9780226257181.001.0001.

Gunningham, N and Sinclair, D 1999. 'Regulatory pluralism: Designing policy mixes for environmental protection', Law E Policy 21(1): 49-76. doi.org/10.1111/1467-9930.00065.

Henne, K 2015. Testing for Athlete Citizenship: Regulating Doping and Sex in Sport. New Brunswick, NJ: Rutgers University Press.

Jerolmack, C and Khan, S 2014. 'Talk is cheap: Ethnography and the attitudinal fallacy', Sociological Methods \& Research 43(2): 178-209. doi.org/10.1177/0049124114523396.

Levi-Faur, D 2011. 'Regulation and regulatory governance', in D Levi-Faur (ed.), Handbook on the Politics of Regulation. Cheltenham, UK: Edward Elgar, pp. 3-21. doi.org/10.4337/97808 57936110.00010 .

Levitt, P and Merry, SE 2009. 'Vernacularization on the ground: Local uses of global women's rights in Peru, China, India and the United States', Global Networks 9(4): 441-61. doi.org/10.1111/j.14710374.2009.00263.x.

Losoncz, I 2015. 'Goals without means: A Mertonian critique of Australia's resettlement policy for South Sudanese refugees', Journal of Refugee Studies, 5 December. doi.org/10.1093/jrs/fev017.

McMichael, P 1996. 'Globalization: Myths and realities', Rural Sociology 61(1): 25-55. doi.org/10.1111/j.1549-0831.1996.tb00609.x. 
Marcus, GE 1995. 'Ethnography in/of the world system: The emergence of multi-sited ethnography', Annual Review of Anthropology 24: 95-117. doi.org/10.1146/annurev.an.24.100195.000523.

Merry, SE 2006. Human Rights and Gender Violence: Translating International Law into Local Justice. Chicago: University of Chicago Press.

Merry, SE 2011. 'Measuring the world: Indicators, human rights and global governance', Current Antbropology 11(S3): S83-95. doi. org $/ 10.1086 / 657241$.

Merry, SE 2015. Ethnography of the global, [podcast], Regulatory Institutions Network Key Thinkers Series, 17 March, The Australian National University, Canberra. Available at: regnet.anu.edu.au/newsevents/podcasts/561/sally-engle-merry-ethnography-global.

Riles, A 2010. Collateral Knowledge: Legal Reasoning in the Global Financial Markets. Chicago: University of Chicago Press.

Scott, C 2010. Regulating in global regimes, Working Papers in Law, Criminology \& Socio-Legal Studies, Research Paper No. 25, University College Dublin, Dublin, pp. 1-17.

Suchman, MC and Mertz, E 2010. 'Toward a new legal empiricism: Empirical legal studies and new legal realism', Annual Review of Law and Social Science 6: 555-79. doi.org/10.1146/annurev. lawsocsci.093008.131617.

Tsing, AL 2005. Friction: An Ethnography of Global Connection. Princeton, NJ: Princeton University Press.

Tusikov, N 2016. Chokepoints: Global Private Regulation on the Internet. Berkeley \& Los Angeles: University of California Press.

Verbruggen, P 2014. Enforcing Transnational Private Regulation: A Comparative Analysis of Advertising and Food Safety. Cheltenham, UK: Edward Elgar. doi.org/10.4337/9781783476855.

Wallerstein, I 2004. World-Systems Analysis. Durham, NC: Duke University Press. 
This text is taken from Regulatory Theory: Foundations and applications, edited by Peter Drahos, published 2017 by ANU Press, The Australian National University, Canberra, Australia. 